\title{
Tingkat Pengetahuan Mahasiswa Universitas Muhammadiyah Mataram Terhadap Penyakit Menular Seksual Tahun 2019
}

\author{
Baiq Leny Nopitasari $^{\text {a, } 1^{*}}$, Abdul Rahman Wahid ${ }^{\text {a,2 }}$, Baharuddin ${ }^{\text {a,3 }}$ \\ a,1,2 Dosen Program Studi Diploma Tiga Farmasi, Universitas Muhammadiyah Mataram, Mataram, Indonesia \\ a,3 Mahasiswa Program Studi Diploma Tiga Farmasi, Universitas Muhammadiyah Mataram, Mataram, Indonesia \\ I baiqleny.nopitasari@gmail.com ${ }^{*}$; ${ }^{2}$ rahman_apt@yahoo.co.id; ${ }^{3}$ BaharyusuffI0@gmail.com \\ *korespondensi penulis
}

\section{INFO ARTIKEL}

Diterima :

4-I2-20I9

Disetujui :

I2-12-2019

Kata kunci:

HIV/AIDS;

Pengetahuan Mahasiswa;

PMS;

\section{ABSTRAK}

Pada tahun 2017 jumlah kasus HIV/AIDS yang ditemukan di NTB mengalami peningkatan dibandingkan tahun 2016. Jumlah kasus yang ditemukan tahun 2016 adalah 62 kasus HIV dan 87 kasus AIDS, sedangkan tahun 2017 ditemukan 98 kasus HIV, dan III kasus AIDS. Jumlah kematian karena AIDS di Provinsi NTB tahun 2016 sebanyak 9 kasus, mengalami peningkatan menjadi 22 kasus tahun 2017. Kota/Kabupaten yang terinfeksi HIV/AIDS paling tinggi yaitu Kota Mataram (39 kasus). Berdasarkan kelompok umur jumlah kasus HIV/AIDS tertinggi yaitu kasus HIV antara 20 - 29 tahun (40,9I \%) dan AIDS antara umur $30-39$ tahun (3I,82 \%). Penelitian ini bertujuan untuk mengetahui tingkat pengetahuan mahasiswa Universitas Muhamadiyah Mataram tentang PMS. Metode penelitian ini adalah observasional deskriptif, dengan pendekatan cross sectional. jumlah sampel dihitung mengunakan rumus slovin, Sampel yang diambil sebanyak 99 sampel yang tersebar di 7 fakultas. Hasil penelitian menunjukan bahwa tingkat pengetahuan mahasiswa Universitas Muhamadiyah Mataram terhadap PMS berada di kategori cukup sebanyak 63 orang (64\%) kategori baik sebanyak 27 orang (27\%), dan kategori kurang sebanyak 9 orang ( $9 \%)$. Kesimpulan dari penelitian ini adalah tingkat pegetahuan mahasiswa Universitas Muhammadiyah Mataram terhadap PMS berada di kategori cukup.

\section{Key word:}

HIV/AIDS;

Students Knowledge;

STD.

\section{ABSTRACT}

In 2017 the number of cases of HIV / AIDS found in NTB increased compared to 2016. The number of cases found in 2016 was 62 cases of HIV and 87 cases of AIDS, while in 2017 there were 98 cases of HIV, and III cases of AIDS. The number of deaths due to AIDS in NTB Province in 2016 was 9 cases, increasing to 22 cases in 2017. The city / regency infected with HIV / AIDS was the highest, Mataram (39 cases). Based on age group, the highest number of HIV / AIDS cases were HIV cases between $20-29$ years $(40.9 \mathrm{I} \%$ ) and AIDS between $30-39$ years ( $31.82 \%)$. This study aims to determine the level of knowledge of students of the University of Muhamadiyah Mataram about STD. This research method is descriptive observational, with cross sectional approach. The number of samples is calculated using the Slovin formula. Samples taken as many as 99 samples spread across 7 faculties. The results showed that the level of knowledge of students of the Muhamadiyah University of Mataram on STD was in the quite category as many as 63 people $(64 \%)$ in the good category as many as 27 people $(27 \%)$, and in the less category as many as 9 people ( $9 \%)$. The conclusion of this study is the level of knowledge of students of the University of Muhammadiyah Mataram against STD is in the sufficient category. 


\section{PENDAHULUAN}

Penyakit Menular Seksual (PMS) merupakan salah satu Infeksi Saluran Reproduksi (ISR) yang di tularkan melalui hubungan kelamin. Infeksi saluran reproduksi merupakan infeksi yang di sebabkan oleh masuk dan berkembangnya kuman penyebab infeksi ke dalam saluran reproduksi. Penyakit Menular Seksual (PMS) umumnya terjadi karena adanya perubahan pola hidup masyarakat. Berdasarkan data dari World Health Organization (WHO) jumlah kasus HIV/AIDS pada tahun 2017 sebanyak 36,9 juta orang, yang terdiri dari 35,I juta orang dewasa (diatas usia I5 tahun) dan I,8 juta anak - anak yang berusia di bawah I5 tahun.. Menurut jenis kelamin persentase kasus HIV/AIDS tahun 2018 pada laki - laki lebih besar di bandingkan perempuan, penderita HIV positif pada laki - laki sebesar $(63,5 \%)$ dan pada perempuan sebesar (36,5 $\%)$. Menurut kelompok umur persentase kasus HIV/AIDS positif terbesar pada penduduk usia produktif (I5 - 49 tahun) tahun 2017 ditemukan 98 kasus HIV, dan III kasus AIDS. Jumlah kematian karena AIDS di Provinsi NTB tahun 2016 sebanyak 9 kasus, mengalami peningkatan menjadi 22 kasus tahun 2017. Kota/Kabupaten yang terinfeksi HIV/AIDS paling tinggi yaitu Kota Mataram (39 kasus). Pada tahun 2015 jumlah penderita HIV/AIDS yang di temukan di kota mataram sejumlah 47 orang. Berdasarkan kelompok umur jumlah kasus HIV/AIDS tertinggi yaitu kasus HIV antara 20 - 29 tahun (40,9I \%) dan AIDS antara umur 30 - 39 tahun (3I,82\%). Program pencegahan Penyakit Menular Seksual (PMS) yang di terapkan di Indonesia masih ditujukan pada kelompok yang di anggap beresiko saja seperti pekerja seks, pengguna pekerja seks, kaum homoseksual, pengguna obat, tranfusi darah dan penggunaan jarum suntik bergantian dan penularan dari ibu ke anak (Perinatal) $^{8}$

\section{METODE PENELITIAN}

Penelitian ini dilakukan dengan menggunakan rancangan penelitian observasional deskriptif. Penelitian ini dilakukan dengan pendekatan cross sectional (belah lintang) dimana pengambilan data dilakukan hanya sekali bagi tiap subyek pada saat wawancara ataupengisian kosioner . Penelitian ini di lakukan di Universitas Muhammadiyah Mataram Jalan $\mathrm{KH}$ Ahmad Dahlan No. I, Pagesangan, Kec. Mataram, Kota Mataram, Nusa Tenggara Barat. 83II5 di bulan Juli 20II. Kriteria Inklusi pada penelitian ini yaitu ahasiswa yang ada di kampus Universitas Muhammadiyah Mataram dan bersedia mengisi kuesioner. Jenis data dalam penelitian ini adalah data primer dan sekunder. Data primer diperoleh secara langsung dari subyek penelitian atau sampel yaitu data identitas responden dan data dari kuesioner, sedangkan data diperoleh secara tidak secara langsung dari subyek penelitian.

Metoda pengolahan dalam penelitian ini dibagi menjadi penelitian dibagi menjadi 4 yaitu, Editing, Coding, Tabulatingdan Scoring. Analisa data yang digunakan dalam penelitian ini adalah dengan menggunakan analisi univariat yaitu terhadap tiap variabel dari hasil tiap penelitian untuk menghasilkan distribusi frekuensi dan presentasi dari tiap variabel. Metoda pengolahan dalam penelitian ini dibagi menjadi 4 yaitu, Editing, Coding, Tabulatingdan Scoring. Analisa data yang digunakan dalam penelitian ini adalah dengan menggunakan analisi univariat yaitu terhadap tiap variabel dari hasil tiap penelitian untuk menghasilkan distribusi frekuensi dan presentasi dari tiap variabel.

\section{HASIL DAN PEMBAHASAN}

Hasil dan pembahasan pada penelitian di fokuskan pada karakteristik dan tingkat pengetahuan mahasiswa Universitas Muhammadiyah Mataram terhadap penyakit menular seksual. Pada akhir pembahasan peneliti juga menyertakan keterbatasan daripada penelitian ini. Pada penelitian ini karakteristik responden dikelompokkan berdasarkan jenis kelamin dan fakultas, yaitu sebagai berikut:

Tabel I. Distribusi Frekuensi Responden Menurut Jenis Kelamin di Universitas Muhammadiyah Mataram tahun 2019.

\begin{tabular}{llll}
\hline No & $\begin{array}{l}\text { Jenis } \\
\text { Kelamin }\end{array}$ & Frekuensi & $\begin{array}{l}\text { Persentase } \\
(\%)\end{array}$ \\
\hline I & Laki-laki & 59 & 59 \\
2 & Perempuan & 40 & $4 \mathrm{I}$ \\
\hline Total & & 99 & I00 \\
\hline
\end{tabular}

Hasil penelitian yang dilakukan di Universitas Muhammadiyah Mataram didapatkan jenis kelamin responden diketahui 59 mahasiswa (50\%) berjenis kelamin laki-laki

dan 40 mahasiswa (40\%) berjenis kelamin perempuan. Dalam hal jenis kelamin, ketidaktahuan perempuan mengenai masalah seksual merupakan tanda kesucian sehingga dikatakan bahwa laki-laki lebih mengetahui masalah seksualitas daripada perempuan karena perempuan lebih pasif sedangkan laki-laki aktif dalam mencari informasi mengenai seksualitas.

Dengan status responden sebagai mahasiswa di harapkan dapat mempengaruhi hasil daripada penelitian ini sehingga sesuai dengan apa yang di harapkan, karena pendidikan adalah yang termasuk salah satu faktor yang mempengaruhi pengetahuan. Menurut Sunaryo (2004) 
Pendidikan berarti bimbingan yang diberikan seseorang terhadap perkembangan orang lain menuju kearah suatu cita-cita tertenu.

Tabel 2. Distribusi Frekuensi Responden Menurut Fakultas di Universitas Muhammadiyah Mataram tahun 2019

\begin{tabular}{clcc}
\hline No & Fakultas & $\begin{array}{c}\text { Ju } \\
\mathrm{ml} \\
\mathrm{ah}\end{array}$ & $\begin{array}{c}\text { Persentase } \\
(\%)\end{array}$ \\
\hline $\mathrm{I}$ & FKIP & $2 \mathrm{I}$ & $2 \mathrm{I} \%$ \\
2 & FIK & 4 & $5 \%$ \\
3 & FAI & 6 & $6 \%$ \\
4 & HUKUM & $\mathrm{I} 2$ & $\mathrm{I} \%$ \\
5 & PERTANIAN & 9 & $9 \%$ \\
6 & TEKNIK & $\mathrm{I} \%$ & $\mathrm{I} \% \%$ \\
7 & FISIPOL & 30 & $30 \%$ \\
\hline & Total & 99 & $100.0 \%$ \\
\hline
\end{tabular}

Tabel 3. Tingkat Pengetahuan Mahasiswa Terhadap Infeksi Menular Seksual di Universitas Muhammadiyah Mataram.

\begin{tabular}{clcc}
\hline $\mathrm{N}$ & Pengetahuan & Jum & $\begin{array}{c}\text { Persentase } \\
\text { o }\end{array}$ \\
& & lah & $(\%)$ \\
\cline { 3 - 3 } I. & Baik & 27 & $27 \%$ \\
2. & Cukup & 63 & $64 \%$ \\
3. & Kurang & 9 & $9 \%$ \\
\hline \multicolumn{2}{c}{ Total } & 99 & $100 \%$ \\
\hline
\end{tabular}

Hasil penelitian menunjukan bahwa tingkat pengetahuan mahasiswa Universitas Muhammadiyah Mataram terhadap infeksi menular seksual berada di kategori baik yaitu sebanyak 27 orang (27\%), cukup yaitu sebanyak 63 orang (64\%) dan kurang yaitu sebanyak 9 orang (9\%). Hasil penelitian ini menunjukan bahwa sebagian besar mahasiswa memiliki tingkat pengetahuan cukup mengenai IMS. Hasil pada penelitian tidak sesuai dengan apa yang di harapkan oleh peneliti yang dimana mahasiswa Universitas Muhammadiyah Mataram seharusnya memiliki pengetahuan yang baik terhadap penyakit menular seksual tersebut karena di sana terdapat Fakultas Kesehatan dengan dua program studi yaitu farmasi dan kebidanan.

Adapun faktor informasi juga dapat mempengaruhi pengetahuan, menurut Nursalam dan Pariana (2004). Informasi akan memberikan pengaruh pada pengetahuan seseorang meskipun seseorang memiliki pendidikan yang rendah tetapi jika ia mendapatkan informasi yang baik dari berbagai media misalnya TV, radio atau surat kabar maka hal itu akan lebih meningkatkan pengetahuan seseorang. Hasil penelitian yang peneliti lakukan di Universitas Muhammadiyah Mataram tentang Penyakit Menular Seksual di peroleh hasil bahwa tingkat pengetahuan mahasiswa berada di kategori cukup yaitu 63 orang (64\%), adapun dari hasil yang di dapat tersebut dimana kemungkinan kurang aktifnya mahasiwa Universitas Muhammadiyah Mataram mencari infomasi mangenai penyakit menular tersebut ataupun kemungkinan lain yaitu mungkin kurangnya pihak Universitas maupun Fakultas Ilmu Kesehatan Universitas Muhammadiyah Mataram dalam hal upaya mensosialisasi dan penyuluhan terhadap dampak dari penyakit menular seksual.

\section{SIMPULAN}

Berdasarkan hasil penelitian yang peneliti lakukan tentang pengetahuan mahasiswa Universitas Muhammadiyah Mataram terhadap Penyakit Menular Seksual tahun 2019 dapat disimpulkan bahwa mayoritas tingkat pengetahuan mahasiswa Universitas Muhammadiyah Mataram berada dalam kategori cukup yaitu sebanyak 63 orang (64\%) baik yaitu sebanyak 27 orang $(27 \%)$, dan kurang yaitu sebanyak 9 orang $(9 \%)$.

\section{REFERENSI}

Ardhiyanti, (20I5). Konsep Dasar HIV/AIDS. Di Bahan Ajar AIDS Pada Asuhan Kebidanan. Edisi Pertama Penerbit : Publisher Yogyakarta

Arikunto, (2013). Prosedur Penelitian: Suatu Pendekatan Praktis. Jakarta: Rineka Cipta

Arikunto,S. (20I0). Prosedur Penelitian Suatu Pendekatan Praktis. Jakarta: Rineka Cipta

Budiman Dan Agus. (2013). Kapita Selekta Kuesiner Pengetahuan Dan Sikap Dalam Penelitian Kesehatan. Jakarta : Selemba Medik

Dinkes Kota Mataram, (2015), Profil Kesehatan Kota Mataram, Dinas Kesehatan Kota Mataram

Djuanda Adhi. (2007). Penyakit Kulit Dan Kelamin, Edisi Kelima Balai Penerbit FKUI. Jakarta

Kemenkes RI, (20II). Pedoman Nasional Penangan Infeksi Menular Seksual

Dinkes NTB, (2017). Profil Kesehatan Nusa Tenggara Barat, Dinas Kesehatan Nusa Tenggara Barat

Hartaji, Dammar A. (2012). Motivasi Berprestasi Pada Mahasiswa Yang Berkuliah Dengan Jurusan Pilihan Oang Tua. Fakultas 
Psikologi Universitas Gunadarma (Tidak Di Terbitkan)

Kemenkes RI, (2018). Profil Kesehatan Indonesia, Kementrian Kesehatan RI

Murtiastutik. (2008). AIDS. Dalam: Barakbah, J. (eds). Buku Ajar Infeksi Menular Seksual. Ed.2. Surabaya University Press; 2 I I-220.

Notoatmodjo, Soekidjo. (2013). Promosi Kesehatan Global. Jakarta: Rineka Cipta.

Notoatmodjo, Soekidjo (2012). Promosi Kesehatan Dan Perilaku Kesehatan. Jakarta: Rineka Cipta.

Notoatmodjo, Soekidjo (20II). Kesehatan Masyarkat : Ilmu Dan Seni. Jakarta: Rineka Cipta.

Notoatmodjo, Soekidjo (20I0). Metodologi Penelitian Kesehatan. Jakarta: Rineka Cipta.

Notoatmodjo, Soekidjo. (20I2). Promosi Kesehatan Dan Perilaku Kesehatan. Jakarta: Rineka Cipta.

Nursalam dan periani. (2004). Buku ajar keperawatan maternitas . edisi 4. Jakarta: EGC

Notoatmodjo, Soekidjo (2005). Promomsi Kesehatan Teori Dan Aplikasi. Jakarta: Rineka Cipta

Nursalam. (20II) Konsep Dan Penerapan Metodologi Penelitian Keperawatan. Jakarta: Salemba Medika

Papalia,Dkk. (2008). Human Development (Psikologi Perkembangan) : Kencana Prenada Media Grup.Jakarta

Santrock, John W.(2002). Life Span Development. Erlangga Jakarta

Siswoyo, Dwi. (2007). Ilmu Pendidikan. UNY Press. Yogyakarta Sunaryo.(2004).Psikologi Untuk Keperawatan. EGC 